\title{
DO AQUEDUTO, DAS FONTES E DAS PONTES: \\ A ARQuitetura da Água na Coimbra de Quinhentos
}

\author{
Milton Pedro Dias Pacheco* \\ miltondpacheco@yahoo.com.br
}

\begin{abstract}
RESUMO: Coimbra, na centúria de Quinhentos, assistiu a uma profunda reforma no conjunto de bens patrimoniais públicos pertencentes à Coroa ou dependentes da Igreja Católica, importantes mecanismos arquitectónicos responsáveis pelo abastecimento de água aos habitantes locais, particularmente às comunidades escolares e religiosas. Este ensaio trata de um conjunto de diversos monumentos relacionados com a arquitectura de água com o propósito de analisar as principais reformas que marcaram um período histórico e um gosto artístico, e que, ainda hoje, um importante testemunho permanece na memória da cidade.
\end{abstract}

PALAVRAS-CHAVE: Coimbra Quinhentista; Arquitectura da água; Monumentos históricos.

\section{INTRODUÇÃO}

Dispondo de uma tecnologia em contínuo desenvolvimento material, o Homem sentiu, desde os primórdios da sua organização social, uma especial necessidade em controlar uma das mais imprescindíveis, embora igualmente intempestivas, forças da Natureza: a Água.

Através de uma das expressões materiais mais singulares do génio humano - a Arquitetura -, foi possível ao Homem domar essa força vital à sua sobrevivência. Para

\footnotetext{
* Doutorando na Faculdade de Letras da Universidade de Coimbra. Bolseiro pela Fundação para a Ciência e Tecnologia. Faculdade de Letras da Universidade de Coimbra. Centro Interdisciplinar de Estudos Camonianos. Centro de História de Além Mar.
} 
transpor as barreiras naturais da água, o Homem construiu pontes, para a transportar aos sítios mais inóspitos, o Homem construiu os aquedutos e as fontes. A esta forma de construir denominamos de arquitetura da água.

A vivência humana moderna foi legando um conjunto edificado em contínua transformação, marcas e testemunhos que evidenciam a evolução dos tempos e das necessidades das suas gentes, registadas nas múltiplas alterações, nas mudanças da utilização e da funcionalidade espacial. Embora inevitáveis, estas transformações levaram à deturpação e à destruição dos modelos arquitetónicos, e também os artísticos, do passado.

Uma panorâmica significativamente completa e deveras elucidativa neste âmbito encontra-se no conjunto de obras arquitetónicas erguidas em Coimbra ao longo de todo o século XVI - sejam elas de grande envergadura, como o aqueduto e a ponte, ou de pequena envergadura, como os muitos fontanários e fontes -, cujo estudo contínuo e análise metodológica asseguram uma percepção bastante enriquecedora do quanto comporta e traduz desde os objetivos da fundação até à atualidade, passando pelas contrariedades a que esteve sujeito e às adulterações sofridas.

A principal cidade do Mondego, a romana Aeminium convertida pelos Árabes em Qulumriyya e depois rebatizada pelos Cristãos de Coimbra ( Pimentel, 2005, p. 190191, 261-265), veio a sofrer grandes transformações materiais e culturais ao longo de toda a centúria de Quinhentos.

Profundamente marcada pelas instituições reais, episcopais e monásticas nos finais da Idade Média, a cidade de Coimbra, nos alvores da Idade Moderna, foi palco de uma séria reforma promovida pela Coroa e efectivada in situ pela casa monástica de Santa Cruz de Coimbra. Se a partir de 1527 D. João III (1502|1521-1557) perspetivou a reinstalação do Studium Generale em Coimbra, onde já estanciara por duas vezes no século XIV, foi frei Brás de Braga, o monge hieronimita, tornado prior-mor de Santa Cruz, quem a concretizou a partir da década de 1530.

A dispendiosa e enérgica reforma universitária joanina, processo que transferira definitivamente a instituição académica de Lisboa para Coimbra, fazia parte dos planos régios de transformar a cidade no principal pólo cultural, num imenso bairro escolar, do Reino. Assim, sérias e importantes obras foram promovidas com o propósito de abrigar a grande massa estudantil que para a principal cidade do Mondego vinha em busca dos graus académicos. 


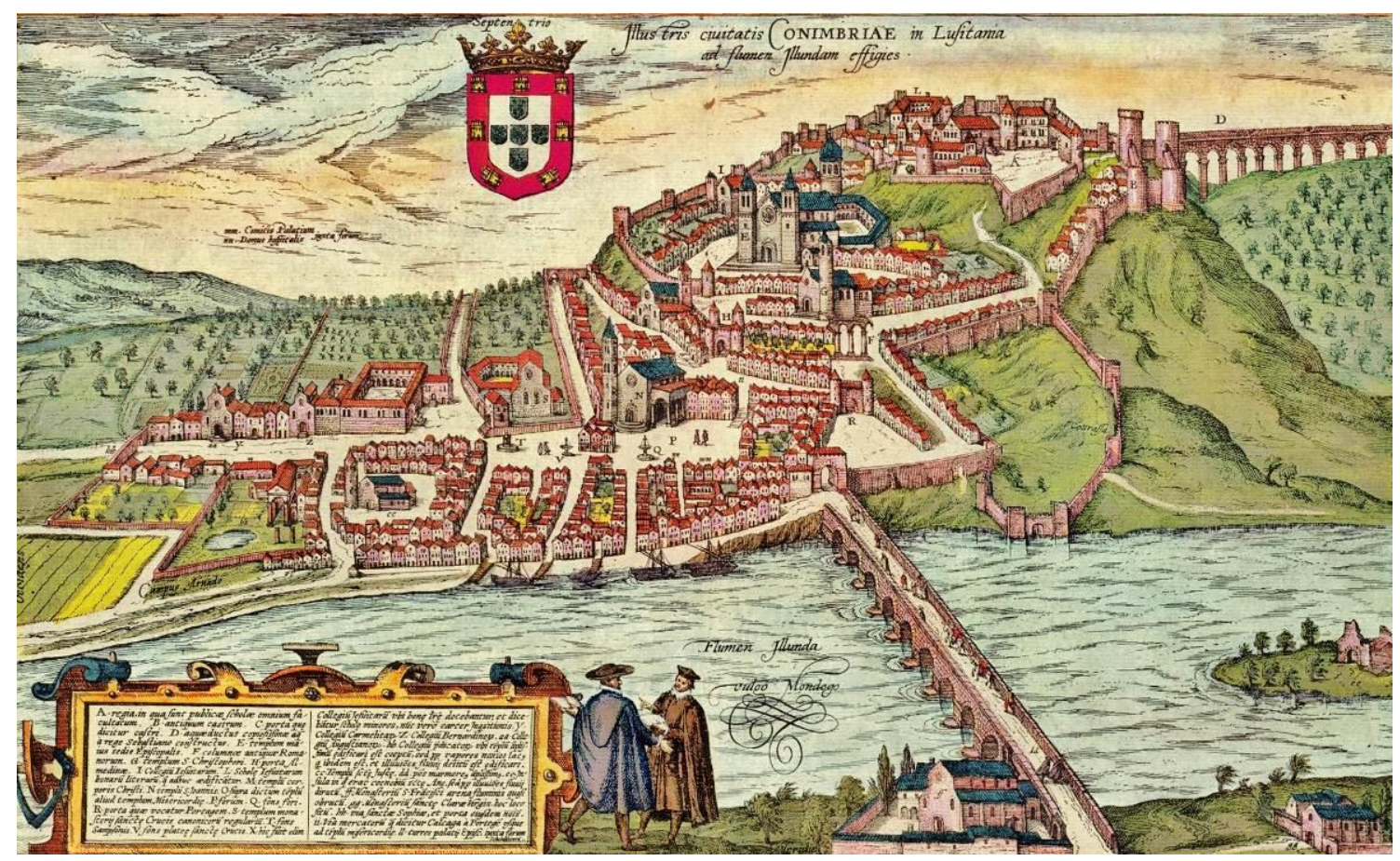

Fig. 1 || Vista da cidade de Coimbra em 1572 | Civitates Orbis Terrarum, vol. V, 1598

Junto do Mosteiro de Santa Cruz, casa reformada nos princípios do século XVI, viria assim a constituir-se o primeiro núcleo da rede de colégios, onde a ciência, a espiritualidade e um conjunto de valores pedagógicos e culturais floresceram no campo de acção e intervenção da Universidade de Coimbra durante cerca de três séculos.

Foi, pois, em torno da Rua de Santa Sofia - a artéria urbana consagrada à Sagrada Sabedoria -, que as diversas Ordens Religiosas nacionais ergueram e sustentaram alguns dos mais importantes colégios, instituições responsáveis pelo contínuo afluxo de estudantes naquela instituição universitária através da administração de um ensino que hoje chamaríamos de preparatório. Junto a este novo eixo urbano, paradigma nacional no planeamento urbano e arquitectónico Quinhentista, também a Coroa decidiu pela construção de uma unidade colegial laica, ainda que a funcionar por um breve período de tempo: o Real Colégio das Artes.

Um novo espírito humanista, imbuído em fortes valores cristãos, irrompia pela cidade e promovia algumas das mais dilectas experiências arquitectónicas do período renascentista português segundo os intentos régios em prol da formação dos seus súbditos para manutenção do seu Império. Modelos arquitectónicos e conteúdos estéticos inovadores, ainda hoje presentes em muitos dos edifícios existentes, sobretudo nos espaços claustrais e religiosos, foram materializados a partir dos debuxos traçados 
por arquitectos e engenheiros, nacionais e estrangeiros, para concretizar uma ideia e um ideal.

Mas dentro em breve uma segunda fase construtiva irrompia no casco antigo da cidade em torno do Paço Real da Alcáçova, a mais antiga residência régia portuguesa que se tornaria na principal morada da Sabedoria, pois aqui se instalou a Universidade a partir de 1537. Uma vez mais, os novos modelos arquitectónicos adoptados viriam renovar a estética urbana conimbricense, sobretudo, com a presença esmagadora do grande complexo colegial promovido pela Companhia de Jesus.

Mas percorramos então a paisagem citadina, da Alta para a Baixa, em busca de algumas dessas formas arquitetónicas, construídas ou reconstruídas na áurea centúria de Quinhentos, em fervorosa ebulição desde a instalação última e definitiva da Universidade, de Lisboa para Coimbra, e que ainda hoje se mantêm bem vivas na memória da cidade.

\section{I - O AQUEDUTO}

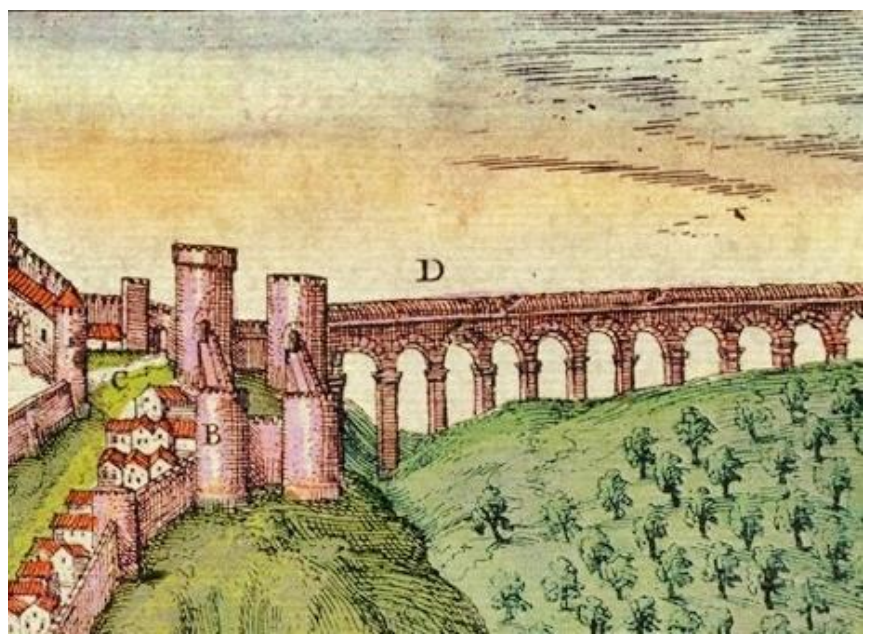

Fig. 2\| Aqueduto da cidade de Coimbra (pormenor) | Civitates Orbis Terrarum, vol. V, 1598

\section{Aqueduto de São Sebastião}

Assumindo-se hoje como um dos marcos históricos mais emblemáticos da cidade, o mais antigo aqueduto de Coimbra, de duplo orago sebástico - pois foi reconstruído por ordem régia do monarca D. Sebastião (1554|1568-1578) e dedicado ao 
mártir romano São Sebastião -, tem as suas origens numa construção que remonta ao período da romanização do território que é hoje Portugal.

Esta estrutura de abastecimento de água potável à cidade, localizada entre a colina onde se erguia o desaparecido Colégio de Nossa Senhora da Conceição e o atual Convento de Santa Teresa e o Fontanário dos Bicos, no Largo da Feira dos Estudantes, em plena Alta Universitária, possui ainda um segundo orago, São Roque, santo que, com São Sebastião, assume o papel de especial protetor contra o flagelo da peste. A escolha destes dois santos patronos está intimamente ligado ao surto pestífero que grassou em Coimbra nos finais da década de 1560, período da construção do aqueduto. Contudo, vingou na história da cidade o patrono onomástico do monarca.

No decorrer da obra, D. Sebastião enviara, em 1568, o desembargador Heitor Borges (séc. XVI) com ordens diretas para proceder ao aprovisionamento da água necessária a distribuir à cidade e à comunidade monástica de Santa Cruz, detentora de grande parte das nascentes urbanas. Contudo, os Cónegos Regrantes, reagindo ferozmente contra as decisões régias, acabaram mesmo por excomungar os oficiais envolvidos e entrar em esgotantes demandas judiciais com a Coroa, levando a sucessivos atrasos nas obras de construção, que, mais tarde, seriam assumidas por um outro desembargador mais enérgico, Martim Gonçalves da Câmara (séc. XVI).

Igualmente excomungado, este oficial não só iria continuar a obra com a celeridade necessária, como iria enfrentar o potentado crúzio, aplicando-lhe pesadas multas pelos entraves causados à obra real, e, sobretudo, pela água usurpada ilegalmente ao município ${ }^{1}$ (Leal, 1874: 326). No seguimento dos trabalhos construtivos, foram demolidos alguns setores do muro da cerca monástica e cortado o arvoredo envolvente junto dos pontos de captação de água para proceder à edificação de pequenas torres, em alvenaria, onde ficariam instaladas as arcas de armazenamento do precioso líquido. Além das expropriações e demolições efetuadas, o oficial régio mandara ainda arrasar o chafariz de São João do Largo de Sansão, que fora erguido em frente à igreja de Santa Cruz durante o priorado de D. Afonso Martim (sécs. XIV-XV), de 1392 a 1414 (LEAL, 1874: 326-327/ CARVALHO, 1942, p.154, 155, 158).

Denominadas de fontes de el-Rei e da Rainha, as nascentes que iriam abastecer o centro da cidade com água potável estavam localizadas junto do quinhentista Colégio de Tomar, sobre o qual foi levantado o edifício da Penitenciária de Coimbra nos finais do século XIX, e, nas proximidades da estrada para Celas. Em local próximo encontrava-se ainda a denominada Fonte da Nogueira, atualmente no Jardim da Sereia que, por alvará 
régio lavrado em 4 de Abril de 1588 e mais tarde reconfirmado em 20 de Abril de 1736, deveria ser vistoriada anualmente pelos oficiais camarários (CARVALHO, 1942, p. $154,200)$.

Inicialmente com uma extensão de aproximadamente de um quilómetro, o aqueduto de São Sebastião ${ }^{2}$, popularmente conhecido como Arcos do Jardim, é hoje constituído por apenas vinte e um arcos dispostos ao longo da Calçada Martim de Freitas e da Praça João Paulo II. Superando uma relativa depressão territorial, os arcos, uns semicirculares e outros abatidos, estão assentes em robustos pilares de faces externas dispostas em degrau que, por sua vez, suportam no topo o canal adutor. Este, coberto por abóbada de berço, só seria desativado no século $\mathrm{XX}$, por volta do ano de 1942. Quanto ao aparelho construtivo podemos indicar a presença de alvenaria de pedra calcária, fixada com argamassa e reboco, recentemente beneficiado.

A partir do setor nascente do atual edifício do Departamento de Matemática da Universidade de Coimbra, a estrutura aquífera continuaria o seu percurso subterraneamente até alcançar o Largo da Feira dos Estudantes, junto da concatedral.

Entretanto, nos finais da década de 1940, no seguimento da reorganização urbanística da Alta para a construção da Cidade Universitária de Coimbra, alguns dos arcos seriam destruídos ${ }^{3}$ para a abertura da atual rua do Arco da Traição, enquanto outros, junto ao Jardim Botânico, acabariam por ser desobstruídos do casario habitacional que havia sido edificado ao longo dos tempos ${ }^{4}$. Quando a Academia Nacional de Belas Artes lançou, em 1947, o Inventário Artístico de Portugal, dedicado à cidade de Coimbra, denunciava-se que "o estado do aqueduto é de meio abandono; encontrando-se bastante prejudicado pelas infiltrações da água do cano", ou seja, ainda se encontrava em funcionamento (CORREIA E GONÇALVES, 1947, p.188).

O arco de honra, igualmente conhecido por Arco de São Sebastião, está disposto obliquamente devido à posição da artéria pública sobre a qual passa, diferenciando-se dos restantes pelo tratamento material e composição artística. Dispõe, pois, na verdade, de um conjunto de inscrições e esculturas, de cariz religioso, que em muito o enobrecem.

Assim, em cada uma das faces da cornija superior, logo acima do fecho do último arco do extremo sul, foram aplicados, em posição central, o escudo com armas reais portuguesas, ladeadas em posição inferior com as lápides referentes à construção do aqueduto com os textos encomiásticos divididos em duas tábuas, datados de 1570 . $\mathrm{Na}$ face sul, orientada para a Alameda Doutor Júlio Henriques, a inscrição surge em 
latim, e na face norte, virada para a Praça Papa João Paulo II, a respetiva tradução em português (Correia e Gonçalves, 1947, p.187).

Nas respetivas lápides do flanco esquerdo, podemos ler:

ANNO . SALVTIS . H
VMANAE . I . 5 . 7 . 0 INVI
CTISSIMVS . LVSITA
NIAE . REX . SEBASTIA
NVS. I . NOBILEM HV
NC . AQVAEDVCTVM
QVI MVLTIS . ANTE .
SECVLIS . PARTIM .
VETVSTATE . CORR
VERAT . PARTIM . EX
CISO . ET . PERFOR
ATO . VRBIS MO
NTE . LONGVA

NO . ANNO . DO SOR

DE . I . 5 . 7 . 0. O INVICT

ISSIMO REI . DOM

SEBASTIAÕ . O . I .

NO . 3 . ANNO DE SEV

GOVERNO . MÃDOV

REEDIFICAR DE NO

VO TODO . ESTE . AQ

VEDVCTO . MAIS . N

OBRE . MẼTE DO Q FO

RA . FEITO . AVIA $M^{\text {TOS }}$.

ANNOS . COMO CÕ

STA . PELO . RASTO Q

Ẽ TODO ELLE . SE AC

HOV CVBERTO DE

E no direito:

HOMINVM . OBLI
VIONE . DELITVE
RAT . A . PRIMIS . FVN
DAMENTIS . ITERVM
NOBILIVS . QVE . A E
DIFICATVM . POPV
LO . CONIMBRICEN
SI . RESTITVIT . ATQUE
DILAPSAS . AQVAS .
IN . COMMVNEM . CI
VIVM . TOTIVSQUE
ACADEMIAE . VS
VM . REDVXIT

ARVORES . E PELOS FV

ROS . DO PENEDO A

TRAS . E DO MÕTE DA

CIDADE.Q.SE ACH

ARAÕ . FEITOS . DO

QVAL . CÕ A LÕGA VE

LHICE . DO T[EM]PO . E G

RÃDE . DESCVIDO

DOS . HOMẼS . NAÕ

AVIA . MEMORIA . E CÕ

ESTE . DEREITO . DESC

VBERTO . RESTITVIO

AS . FÕTES . ESPALHAD

AS . AO . COMṼ . VSO DA

Milton Pedro Dias Pacheco. Do AQUEDUTO, DAS FONTES E DAS PONTES: 
Resumindo o conteúdo dos testemunhos epigráficos, podemos salientar o cuidado do monarca em dotar de água potável a principal zona urbana frequentada pela comunidade escolar, que fora responsável pelo crescimento imediato do núcleo urbano conimbricense.

A coroar o respetivo arco principal, sobre o canal adutor, ergue-se um pequeno templete, de planta trapezoidal, composto por colunas dóricas que suportam uma cúpula e lanternim superior. Em cada um dos flancos, cada um dotado com o respectivo nicho, encontra-se as esculturas dos oragos do aqueduto: a de São Sebastião disposta na face sul, e a de São Roque, na face norte.

Desconhecemos, no entanto, o nome do arquiteto responsável pelo projeto, assim como o dos mestres-de-obras que conduziram os diversos trabalhos construtivos. Embora sem grande consenso, surge, entre alguns autores, apenas um nome, o de Fillipo Terzi (1520-1597), um engenheiro militar italiano, natural de Bolonha, que veio assumir funções no Reino ao serviço do monarca D. Sebastião. Ora tendo em conta que a presença de Fillipo Terzi só é documentada a partir de 1577, um ano antes da desastrosa campanha militar de Alcácer Quibir, a qual acabaria por integrar enquanto engenheiro militar e da qual resultaria o seu cativeiro, julgamos que esta obra não possa pertencer ao artista bolonhês (Pacheco, 2010, p.121-124).

Além do aqueduto de São Sebastião, erguido em pleno coração citadino, existe ainda uma outra estrutura mais recente. Trata-se do aqueduto projetado por Manuel Alves Macomboa (?-1815) nos finais do século XVIII, destinado ao abastecimento do Mosteiro de Santa Clara-a-Nova, com a mãe d'água localizada no lugar da Granja de Santa Clara, mas que por motivos cronológicos foi excluído do presente estudo.

\section{II - AS FONTES}




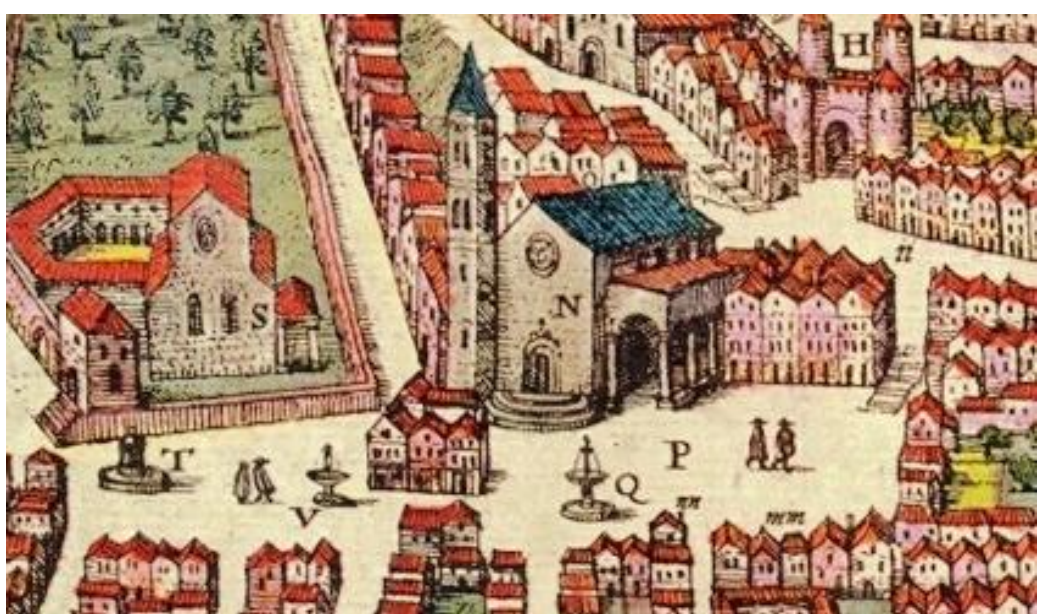

Fig. 3|| Fontes no largo dos colégios e mosteiro de Santa Cruz (pormenor) । Civitates Orbis Terrarum, vol. V, 1598

\section{Chafariz do Largo da Feira dos Estudantes}

Culminaria a conduta do aqueduto de São Sebastião no chafariz do Largo da Feira dos Estudantes. Embora as fontes documentais não permitam conhecer a data precisa para a sua construção julgamos que a mesma tenha sido edificada no seguimento da conclusão do reservatório para a água transportada pelo aqueduto, a qual surge como parte integrante.

Neste terreiro, onde era organizada a feira de exclusiva frequência aos académicos e escolares universitários, foi então construído, entre 1570 e 1572 [Carvalho, 1957: 177-178], o depósito de água. Este não só veio a permitir o funcionamento do fontanário local - que a história viria a consagrar como Fonte dos Bicos devido aos motivos decorativos em ponta de diamante salientes que ornamentavam a sua frontaria principal -, como garantiu o abastecimento de outros equipamentos aquíferos, como o Chafariz da Sé, onde existia um segundo reservatório para levar água até ao fontanário localizado na Praça de São Bartolomeu (CARVALHO, 1942, p.166).

Alguns anos mais tarde, este mesmo reservatório acabaria por ser dotado com os encanamentos destinados a abastecer o vizinho Palácio da Mitra Episcopal de Coimbra e outros institutos religiosos existentes na Alta citadina, como os colégios de Jesus, o da Sapiência e o da Estrela. De acordo com as informações recolhidas, nos anos de 17151858, julgamos que o depósito do fontanário do paço episcopal, e, provavelmente o da catedral, a Sé Velha, eram abastecidos durante o dia, sendo os depósitos dos colégios 
dos Jesuítas e dos Agostinhos durante o período noturno (CARVALHO, 1957, p. 169170).

Identificado como fons fori na antiga gravura da obra de Georg Braun (15411622), dedicada à cidade de Coimbra e impressa em 1572, o fontanário da Feira dos Estudantes terá sido construído no seguimento da carta régia outorgada por D. Sebastião em 7 de Maio de 1573, no qual ordenava a construção do chafariz da Feira (CARVALHO, 1957: 167). Tratar-se-ia, muito provavelmente, de uma ampliação ou reedificação material, pois, quer esta bica de água, quer a localizada junto da catedral de Santa Maria de Coimbra, já são mencionadas em datas anteriores.

No que diz respeito à composição arquitetónica do primitivo fontanário da Praça da Feira pouco ou nada sabemos. Teria, ao que parece, três bicas para o fornecimento de água, número que manteria ao longo da sua existência, mesmo após as obras de beneficiação de que foi alvo, em 1747 ou em 1864, a primeira para renovação do frontispício e a segunda para a colocação das armas da cidade (CARVALHO, 1957: 170-171).

Até à destruição do Fontanário dos Bicos, ocorrida durante a construção da Faculdade de Medicina da Universidade de Coimbra e do Instituto de Medicina Legal, nos finais da década de 1940, a água ainda era utilizada para regas e limpezas locais.

\section{O sistema hidráulico do Paço da Mitra Episcopal de Coimbra}

A irregularidade volumétrica do primitivo Palácio da Mitra Episcopal de Coimbra, onde em 1912 foi instalado o Museu Nacional de Machado Castro, resulta de um conjunto de sucessivas construções e ampliações efetuadas ao longo de diversas épocas, desde o século XII aos inícios do século XX. Em todo o conjunto edificado é possível verificar a expansão das áreas residenciais, a norte, para o flanco sul da área do criptopórtico, anteriormente ocupado pelas cavalariças, celeiros e outras dependências e sua cristalização sob as formas e fórmulas arquitetónicas responsáveis pela anulação das características medievais ${ }^{5}$.

Assim, a inexistência de vestígios materiais do período manuelino no flanco sul do monumento aponta para que a construção das primeiras dependências residenciais neste setor sejam da responsabilidade de D. Afonso de Castelo Branco (c. 1522-1615), 
quando em Coimbra, para os finais do século XVI, despoletavam os novos modelos artísticos do Maneirismo.

Não dispondo de nenhum documento que assinale a data exata de início da colossal campanha levada a cabo pelo prelado residencial sabemos seguramente o seu término através do dístico colocado no portal de entrada, no ano de 1592. Todavia, é no precioso registo biográfico redigido por João d'Almeida Soares (sécs. XVI-XVII), cerca de vinte anos após a morte do prelado de Coimbra - Vida e morte de Dom Affonço Castelbranco Bispo de Coimbra, Senhor de Coja e Alcayde mór de Arouca ${ }^{6}$ [sic], Vizo Rey deste Reyno dito Portugal -, que somos informados da rapidez com que as referidas obras foram promovidas, do valor gasto na obra, assim como de outras referências, dados e esclarecimentos do quotidiano vivenciado na residência episcopal (BACL, Soares: 66-67/ Castro, 1867: 86-87).

Dispondo dos rendimentos da Mitra, avaliados em 50 mil cruzados, D. Afonso de Castelo Branco, muito provavelmente em 1585/1586, "com toda a brevidade fez logo pôr em effeito o paço, q̃ hoje em rezp. ${ }^{\text {to }}$ do outro chamam novo, que lhe passou de outenta mil cruzados com suas galarias, chafarizes, patios, e todos os mais requezitos p. $^{\text {a }}$ apozento de hum grande senhor, nam tirando a estas obras comtudo a porsam dos pobres, que assi nam haviam elles de perder". Conta ainda o biógrafo que o principal motivo que esteve na base desta reforma era a ruína em que o edifício se encontrava: "como lhe enfadava dinheyro encantado não se contentou com o Paço em q̃ viviam seus antecessores, $\tilde{\mathrm{q}}$ realmente nam estava já muito decente $\mathrm{p}^{\mathrm{a}}$ tanta renda, e tanta authoridade; mas elle hera Prinçepe, o animo de Prinçepe, as obras de Prinçepe, e as esmolas de Santo" (BACL; SOARES, p.66-67).

Entretanto, o erudito conimbricense Martins de Carvalho (1861-1921) sugere que as obras efetivadas sob a égide do grande prelado conimbricense tenham tido início em 1585, no ano em que entrou como bispo residencial na diocese de Coimbra. É possível que o autor se tenha baseado na obra de João d'Almeida Soares, quando este escreveu que, com a maior prontidão, "fez logo pôr em effeito o paço [que] chamam novo", e, com mais alguma certeza, no possível contrato assinado entre o prelado e a edilidade para o abastecimento de água ao edifício episcopal (BACL, SOARES: 66-67/ CARVALHO, 1957: 168/ SILVA, 1972-73, p. 461).

Acreditamos, assim, que todo o processo construtivo no Palácio da Mitra, "com suas galarias, chafarizes, patios", tenha começado efetivamente entre os finais de 1585 e os inícios do ano seguinte, com a realização dos acordos estabelecidos entre as diversas 
autoridades, a elaboração de projetos e a obtenção das mais variadas licenças junto da vereação, a qual o prelado viria a integrar (LOUREIRO, 1940: 52/ BOTELHO, 1873: 34/ BRITO, 1944: 116). Será que podemos relacionar as avultadas somas de dinheiro doadas pelo prelado à vereação de Coimbra com a obra de encanamento de água do paço? Seriam somente doações ou também pagamentos uma vez que o prelado veio a adquirir o direito perpétuo de abastecimento de água ao Palácio Episcopal? [MNMC ${ }^{7}$ / RODRIGUES, 1984, p. 119).

A título de curiosidade achámos oportuno apresentar os avultados donativos legados pelo prelado com o propósito da manutenção de infra-estruturas públicas citadinas. Expiradas as doações feitas à edilidade pelos bispos D. frei João Soares (?|1545-1572) e D. Manuel de Menezes (?|1573-1578), com 50 mil réis e 10 mil réis anuais respectivamente - destinadas à manutenção de fontes e aquedutos, pontes e calçadas -, D. Afonso de Castelo Branco, em 31 de Julho de 1591, renovou o gesto dos seus antecessores ao conceder ao município a quantia de 6 mil cruzados (CARVALHO, 1994: 40-41/ GOUVEIA, 1875: 166/ ALMEIDA, 1924: 60-61/ AHMC ${ }^{8} / \mathrm{PACHECO}$ 2009: 98].

Estas doações, quase sempre direccionadas para arranjo das infra-estruturas públicas, sendo a mais antiga conhecida a que o bispo D. Jorge (?|1338-1357) efetuou em 1344, no valor de 120 libras, terão contribuído largamente para que os prelados fossem convidados a participar ativamente na administração da edilidade ao longo dos séculos (GOUVEIA, 1875, p. 6).

Mais tarde, a 10 de Setembro de 1611, D. Filipe II de Portugal (1578|1598-1621) despacharia um alvará favorável à Mitra de Coimbra, em resposta a uma contenda despoletada com a edilidade relacionada com o abastecimento público de água ao paço ${ }^{9}$, a partir do reservatório localizado na Feira dos Estudantes: "Vista a forma do contrato que esta cidade fez com o bispo-conde no ano de oitenta e cinco e oitenta e oito sobre a água de que agora se trata que vai ao seu pátio [...] não se poderá mudar o curso e cano desta água que ora vai ao pátio do dito bispo-conde por outra nenhuma parte diferente daquela por onde ora vai [pela rua do Rego d'Água] o que haverá lugar em vida do dito bispo-conde na forma do dito contrato" (FIGUEIREDO, 1996: 276/ CARVALHO, 1957: 165-169/ ABREU, 1807: 139]. Ficava esta rua, chamada do Rego d'Água, entre os contíguos prédios de habitação e da antiga escola primária, ou seja, entre o Largo da Sé Nova e o Largo do Bispo. 
A partir daquele documento, podemos aferir não só das duas datas contratuais, 1585 (assinatura do contrato?) e 1588 (conclusão da obra de encanamento e de abastecimento de água?), como também da existência de um fontanário erguido no pátio principal da residência episcopal. Esta infra-estrutura deve então ser considerada como um verdadeiro luxo entre as moradas habitacionais localizadas na Alta de Coimbra ao tempo, pois não só era reveladora da introdução do novo gosto pela arquitectura da água para recreio dos seus proprietários, como comprova a existência de estruturas similares que dotaram com melhores condições higiene os seus residentes.

A cisterna do paço, identificada aquando das campanhas de arqueologia realizadas entre 1992 e 1997 (MNMC ${ }^{10} /$ CARVALHO, 1998,p. 26, 39,43), foi edificada, segundo a opinião de Pedro Carvalho (1967), a partir do isolamento da galeria norte do piso superior do criptopórtico romano, que fornecia de água a residência episcopal a partir do segundo pátio. Abastecida por águas pluviais, ou manualmente, o depósito poderá ter sido reaproveitado durante as obras promovidas por D. Afonso de Castelo Branco quando dotou o edifício com água potável canalizada a partir da Fonte dos Bicos no Largo da Feira dos Estudantes.

Apesar de não serem conhecidos dados arqueológicos, é conhecida nos arquivos da Biblioteca Geral da Universidade de Coimbra a planta da conduta que permitiria o transporte da água entre o paço e a "caza da agoa", levantada, muito provavelmente, em 1745, ano em que o repartidor camarário da água passaria carta de propriedade sobre parte do "cano da feira" para o Paço do Bispo e Colégio da Companhia de Jesus (GOUVEIA, 1875, p. 23, 151).

Quase um século mais tarde, entre 1672 e 1683, o chafariz erguido no pátio principal do Palácio da Mitra Episcopal de Coimbra por D. Afonso de Castelo Branco seria substituído por um outro, patrocinado durante o episcopado de D. frei Álvaro de São Boaventura (c.1628|1672-1683). Erguido no pátio central, o fontanário apresenta tanque circular com coluna central dotada de dois pratos, de diferentes dimensões e ornamentados com quatro mascarões cada um, tendo no topo as armas episcopais do seu encomendante.

Além das estruturas arquitetónicas aquíferas patrocinadas pelos prelados conimbricenses em toda a cidade sabemos que na sua propriedade localizada junto da Quinta da Mal-Lavada já funcionava, durante a centúria de Quinhentos, uma bica de água, a Fonte do Bispo (CARVALHO, 1942, p. 193-194). Muito provavelmente, iguais 
estruturas seriam construídas na Quinta de São Martinho do Bispo, onde a Mitra dispunha da sua muito rentável quinta de recreio $(\operatorname{PACHECO}(\mathrm{A})$ : 16-17).

\section{O chafariz da Catedral de Santa Maria de Coimbra}

Erguido no quadrante noroeste do adro da catedral de Santa Maria de Coimbra, o fontanário conhecido como chafariz da Sé Velha deverá ter sido erigido na década de 1570, entre os anos de 1573-74, no seguimento do despacho régio emitido por D. Sebastião em 7 de Maio de 1573, ao determinar a construção dos chafarizes nos largos urbanos da Feira dos Estudantes e da sé (CARVALHO, 1942, p.167). Dotado apenas de uma bica, a estrutura aquífera acabaria por ser aumentada e beneficiada, entre 1610 e 1611, durante o episcopado de D. Afonso de Castelo Branco. Esta campanha acabaria por acrescentar uma segunda bica e alterar a estrutura primitiva com a colocação das suas armas de fé e as do seu antecessor D. Jorge de Almeida (1458|1483-1543), elementos heráldicos que hoje enriquecem as coleções de escultura do Museu Nacional de Machado de Castro.

Contudo, o fontanário da Sé que se encontra reproduzido na obra de Ferdinand Denis (1798-1890) não é o mesmo que teria sido patrocinado pelo prelado D. Afonso, mas sim o que resultara das obras de reparação ocorridas em 1747, uma vez que fora retirada uma das bicas e colocada uma carranca barroquizante [Carvalho, 1942: $171,173]$.

\section{Fontanário do Claustro da Manga do Mosteiro de Santa Cruz de Coimbra}

Distinguindo-se no apoio espiritual e amparo material à população da região durante a consolidação das fronteiras do recém-formado Reino de Portugal, o Mosteiro de Santa Cruz de Coimbra, um dos espaços prediletos da monarquia portuguesa onde repousa o Rei Fundador, foi nos alvores de Quinhentos alvo de duas profundas reformas arquitetónicas promovidas pela Coroa.

A campanha promovida por D. Manuel I (1469|1495-1521), durante o priorado de D. Pedro Vaz Gavião (?-1516), incidiu na reconstrução dos espaços mais emblemáticos do mosteiro crúzio, nomeadamente na igreja com o conjunto funerário 
dos primeiros dois monarcas portugueses. No claustro principal, o do Silêncio, erguiase "dentro em o ceo hũa fõte dagoa q cõtinuamente corre em hũa bacia de pedra laurada de bestiaẽs". Entretanto o fontanário manuelino, rodeado de laranjeiras e ervas "muy cheirosas \& preciosas" [Révah, 1957: 9 v], acabaria por ser desmantelado e substituído pela actual estrutura setecentista. Mas como seria o fontanário manuelino levantado sob a direcção artística dos mestres Marcos Pires e Boytac?

Segundo o que a tradição consagrou, a Fonte da Manga deve o seu nome ao monarca D. João III, que refugiado, em 1527, na cidade do Mondego em virtude de surto pestífero desencadeado na capital, esboçou na manga do seu gibão o plano do fontanário que pretendia ver erguido no claustro nascente do complexo monástico [Révah, 1957: $11 \mathrm{v}$ ].

Apesar desta origem lendária, elaborada em 1541 por Francisco de Mendanha (séc. XVI), este magnífico exemplar de arquitetura da água resultou da reorganização material operada no complexo crúzio por frei Brás de Braga (c.1500-1559) em 1528, um ano após a estadia régia. Seria este prior hieronimita, nomeado agente régio pelo monarca, o responsável pelo programa da reforma da grande casa dos Cónegos Regrantes de Santo Agostinho à beira do Mondego e da transferência da Universidade de Lisboa para Coimbra.

Com "duzentos palmos de cõprido \& quinze de largo", o espaço claustral, um dos três existentes no mosteiro e em torno do qual se congregavam o dormitório, a enfermaria e as oficinas tipográficas monásticas quinhentistas, foi dotado de um templete de planta centralizada, com uma fonte de "agoa muy doce", de fornato circular no interior (RÉVAH, 1957,p. 12; CRAVEIRO, I, 2002,p. 125-126). Sobre as oito colunas coríntias, dispostas equilibradamente entre si, assenta a abóbada rematada por lanternim e dotada, no entablamento, por oito gárgulas, número que entretanto se duplica aos pares no topo de cada uma das escadas, perfazendo assim dezoito peças esculpidas segundo a temática do bestiário ${ }^{11}$.

Elevada numa plataforma rodeada por tanques de água e hortos ajardinados, com limões, limas, cidras e outras frutas, por entre as quais surgem quatro panos de escadas de acesso, a estrutura principal está ligada por arcobotantes a quatro torreões circundantes, de formato cilíndrico e com estreitas frestas de iluminação de vidraças coloridas. A descrição de 1541 revela ainda que os quatro oratórios estavam dotados de portas que "sam pontes leuadiças cõ que os religiosos se fechã quando orã " (RÉVAH, 1957, p. 12 v). Edificados como pequenos oratórios independentes e eremíticos, cada 
altar fora dotado com um baixo-relevo, em calcário de Ançã, representando quatro grandes santos eremitas da tradição cristã: São João Baptista no deserto; São Jerónimo penitente; São Paulo o eremita e Santo Antão tentado pelo demónio (GONÇALVES, 1984: 246-247).

De acordo com a leitura iconológica realizada por Nelson Correia Borges (1942), o fontanário da Manga está imbuído de um forte simbolismo religioso associado com a Fonte da Vida - a fons vitae -, que jorra do centro do Universo para os quatro tanques, numa clara alusão aos quatro rios do Paraíso (BORGES, 1987, p.115). Este seria assim um ambiente recriado pelos monges destinado à contemplação, à oração e à reflexão interior. É, no entanto, muito curiosa a nota escrita pelo cronista quinhentista que considera a obra da "fonte artificiosa" como uma das "quatro marauilhas do mũdo", ainda que tenha sido causa de muitas enfermidades entre a comunidade monástica, motivo pelo qual estaria desactivada aquando da visita régia de D. Sebastião em 1570 (RÉVAH, 1957, p.11 v; Boletim, 1958, p. 32).

O projeto é atribuído ao arquiteto e escultor francês João de Ruão (?-1580) ativo em Coimbra desde 1518. Embora persistam algumas dúvidas quanto à autoria do projecto arquitetónico é seguro o envolvimento de Ruão e seus oficiais na execução dos quatro painéis retabulares dos oratórios, trabalho feito sob a influência das gravuras de Lucas de Leyde (?-?), que lhe rendeu a quantia de 140.600 reais. Ao mestre Jerónimo Afonso (sécs. XV-XVI) foi confiado o labor das cantarias pela quantia de 30.000 reais (RÉVAH, 1957: 12 v; MARKL e PEREIRA, 1986, p. 66).

Recorrendo aos novos mecanismos da engenharia hidráulica moderna, a construção dos tanques e do sistema de canalização, a cargo de Pero de Évora (séc. XVI), Diogo Fernandes (séc. XVI) e Fernão Luís (séc. XVI), ficaria firmada por contrato de Setembro de 1533. Dois anos depois, em 1535, continuavam os trabalhos de carpintaria levados a cabo por João Afonso (séc. XVI) [Craveiro, I, 2002: 22, 126-127].

De acordo com a escritura outorgada por frei Brás de Braga, em 1533 documento bastante pormenorizado acerca dos trabalhos a executar, permitindo assim compreender os processos construtivos coevos -, os ditos pedreiros ficaram então encarregues de:

Primeiramente se obriguarã abrir os alliçeses das paredes que ham de fazer os ditos tamques tã larguos que amtre a terra e as paredes posa ãdar huum ofiçiall para guarneçer mujto bem e direitos as ditas paredes em preto. E habrirem e desemtulharem todos os tamques de largura de dez palmos por baixo, e o comprimento delles será o que 
bem pareçer ao dito padre e fumdadas as paredes as subiram Aquella altura que o dito padre mandar, e as ladrilharam muyto bem por cima de...

E se obriguarã ha fazerem nos ditos tanques huua fiaada de aluenarja muyto bem feyta e farta de call e por çima desta fiada fazerem sua arguamasa muy bem feyta cõposta e forte dãdolhe porem os ditos padre e veedor as cousas necesarjas para a dita arguamassa. E por çima da dita Arguamasa se obrigarã a guarnecer todos os ditos tamques e paredes delles de maneira que fiquem bem vedados e seguros.

E bem asy se obrigaram a ffazer todos os alleçeçes para os cubelos da maneira que ho dito padre lhe mandar e asy as aluenarjas delles e abobodas de tigello daltura que lhe for mandado e asynado por o dito padre, e a guarneçer e pinzellar muy bem toda a dita aluenarja e cubelos e abobodas $\mathrm{E}$ a asentar os degraos de pedra que vam sobre as abobodas que fazem a volta.

E asy se asy se [sic] obriguauã majs a abrir e desemtulhar a sota muyto bem e em ella ffazer sejs buracos hem as partes que lhe asynar o dito padre e em os ditos buracos encastoar canos de pedra ou alquatruzes quall quer destas que lhes derem" (Garcia,1923, p. 87-88).

Após a demolição do corpo norte do claustro, na posse da Câmara Municipal de Coimbra desde 1839, já no século XX, o Jardim de Manga ganhou acesso direto a partir da Rua Olímpio Nicolau Rui Fernandes, e, através de uma ampla escadaria, no extremo sul, da Rua Martins de Carvalho. Embora já mutilados, três dos quatro pequenos retábulos teriam sido retirados em data desconhecida, muito provavelmente nos inícios do século XX, acabando por ser recolocados no lugar original em 1957, após as obras de requalificação das estruturas e do espaço envolvente, tendo sido entretanto transferidos e incorporados nas coleções do principal museu da cidade ${ }^{12}$.

No espaço do Mosteiro de Santa Cruz a arquitetura da água iria continuar a florescer nos séculos seguintes, sobretudo, na centúria de Setecentos, durante o governo do prior-mor D. Gaspar da Encarnação (séc. XVIII), o responsável pela renovação do grande espaço ajardinado da cerca monástica crúzia, com a construção de múltiplos jogos de águas: cascatas, fontes e lagos no actual e aprazível Jardim da Sereia (LEAL ${ }^{13}$, 1874, p. 327).

\section{Lavabo do Colégio de Nossa Senhora da Graça}


Nos finais da primeira metade do século XVI, no seguimento da reinstalação dos Estudos Gerais em Coimbra no ano de 1537, foi estabelecida uma enérgica rede de institutos colegiais destinados a instalar e apoiar o acentuado afluxo estudantil que com a Universidade viera.

Entre os primeiros colégios edificados na Rua de Santa Sofia, ao longo de todo este período de fortalecimento e crescimento da Universidade de Coimbra, encontravase o Colégio de Nossa Senhora da Graça da Província da Ordem dos Eremitas Calçados de Santo Agostinho. Cedidos os terrenos por parte do Mosteiro de Santa Cruz, as obras do colégio iniciaram-se em 13 de Janeiro de 1543 segundo os debuxos do arquiteto biscainho Diogo de Castilho (?-1574), sob a supervisão do agostinho castelhano frei Luís de Montoya (?-1569). Concluídas as obras do complexo colegial cinco anos depois, os trabalhos do templo anexo continuariam até 1555 (ALONSO OSA, 1991, p. 330).

Esta construção, inserindo-se no contexto dos modelos religiosos regulares, observa a tipologia do edifício de ensino eclesiástico urbano, reservado e fechado sobre si próprio, no seguimento dos centros intelectuais e culturais medievais, como evidenciam as presentes estruturas educacionais, durante muitos séculos específicas das inerências da Igreja. Os seus preceitos arquitetónicos, destinados ao usufruto de uma comunidade escolar, manifestam assim claramente a concretização dos ideais de vida religiosa comunitária (Borges, 1998, p. 31).

Assim, dotado de pouquíssimos acessos ao exterior, o colégio foi organizado em torno de um claustro, o centro vital da comunidade estudantil, a partir do qual se desenvolvem as principais áreas dedicadas ao ensino e ao culto e, por tal motivo, com ligação direta ao templo, ao refeitório e às áreas internas do colégio, como os espaços escolares, livraria e dormitórios. Em Junho de 1548, Pero Luís (séc. XVI) e Jerónimo Afonso (séc. XVI), este último interveniente nas obras do fontanário da Manga, reportavam a conclusão dos trabalhos construtivos do claustro (CRAVEIRO, 2002,p. 253).

Seguindo o modelo comum utilizado nas casas monásticas da Ordem de Santo Agostinho (BORGES, 1998, p.50), encontra-se no ângulo nordeste do pátio claustral a casa do lavabo, uma pequena divisão reservada ao lavatório, imprescindível às práticas higiénicas, mas também rituais, que antecediam as refeições organizadas no amplo refeitório dos escolares e no dos novatos. 
Atualmente, acede-se à estreita dependência, de formato retangular, a partir de um portal de verga de idêntico formato, moldurada e lisa, guarnecida por guarda de forjado, de aspecto recente. No seu interior, no vão aberto na parede fronteira e dotado de um arco de volta perfeita, encontra-se o lavabo. Este é constituído por um reservatório rectangular moldurado, embutido na parede, dotado de três mascarões, de sabor renascentista, dos quais saem as respectivas bicas de água. Em baixo está a bacia, rectangular e seccionada, assente numa pilastra, e, no topo da estrutura, encontra-se o bocal de abastecimento, delimitado por elaborado frontão, ladeado por dois enrolamentos vegetalistas e encimado por um coração flamejante, símbolo adoptado pelos religiosos da Ordem de Santo Agostinho. Contudo, o tipo de ornamentação utilizado na seção superior do lavabo é revelador de um gosto mais próximo dos cânones maneiristas do que dos renascentistas, o que implica uma possível intervenção ou, até mesmo, execução, para os finais do século XVI.

\section{III - A(S) PONTE(S)}

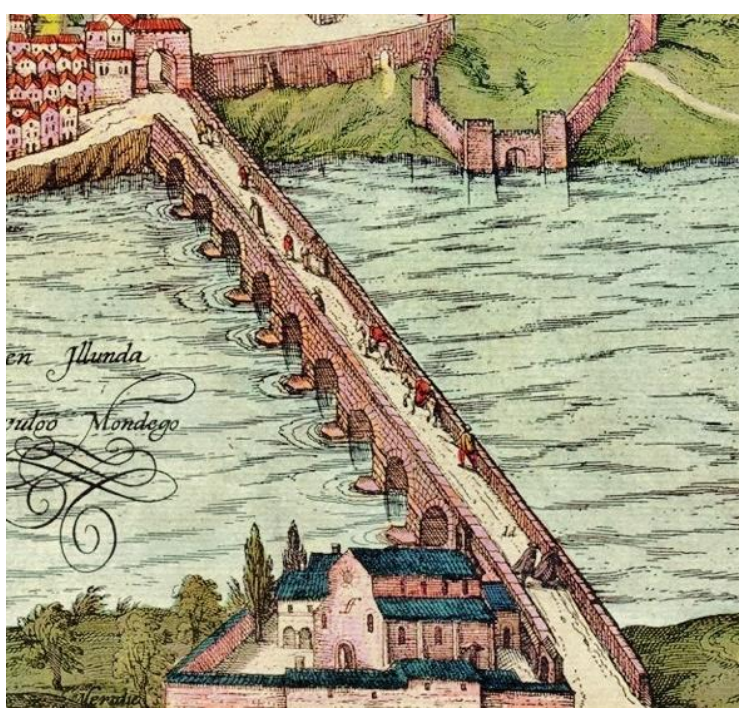

Fig. $4 \|$ Ponte da cidade de Coimbra (pormenor) | Civitates Orbis Terrarum, vol. V, 1598

\section{Ponte Real de Coimbra}

Regressando aos conjuntos arquitetónicos de grande envergadura, debrucemonos agora sobre a antiga ponte edificada sobre o Rio Mondego, curso fluvial que 
durante séculos permitiu as trocas comerciais e fertilizou os terrenos aluviais mas assolou constantemente, com as suas tempestuosas inundações, os burgos da Baixa citadina e o de Santa Clara.

Estabelecendo a vital ligação entre os dois lados do rio Mondego, a antiga ponte real foi durante séculos a principal entrada em Coimbra, integrando a via terrestre que ligava Lisboa ao Porto - não no trajeto conhecido através das ruas Ferreira Borges e Visconde da Luz -, mas sim através da íngreme Couraça de Lisboa.

Alguns autores defendem a tradição de que as primeiras pontes construídas sobre o Mondego tiveram, tal como no caso do aqueduto citadino, uma origem romana. Entretanto, iniciada a formação do Reino de Portugal, consta que D. Afonso Henriques (c. 1109|1139-1185) mandara reconstruir a ponte no ano de 1132, seguida dos arranjos planeados por D. Sancho I (1154|1185-1211) em 1210, e pelos seus sucessores ao longo de toda a Baixa Idade Média. Estas sucessivas reconstruções ficar-se-iam a dever, sobretudo, devido aos danos provocados pela força das correntes, como se verifica numa carta enviada por D. João II (1455|1481-1495) ao conselho da cidade: "a ponte dessa cidade está muito danificada das cheias passadas e em mui grande perigo" (BRITO, 1947, p. 4).

Com efeito, os autores mais fidedignos apontam para uma intervenção sabiamente estruturada durante o reinado de D. Manuel I, nos alvores do século XVI. Segundo o que as fontes documentais apontam, o monarca, após a visita realizada a Coimbra na companhia da Família Real no ano de 1506, ordenara aos mestres Boytac (sécs. XV-XVI) e Mateus (sécs. XV-XVI), em Setembro de 1510, de promoverem os estudos necessários para o "corregimento da ponte". A campanha seria efetivamente concluída nos três anos seguintes, pois, em 1513, a ponte estava aberta ao tráfego [Brito, 1947: 4-5].

A estrutura ficava assim a dispor de vinte e quatro arcos, executados em pedra, provavelmente em calcário dolomítico da cidade, inclusive as guardas laterais, que na seção correspondente ao oitavo arco eram encimadas em cada um dos flancos pelas esferas armilares do monarca reinante. No extremo sul, já próximo da margem de Santa Clara, parte do troço da ponte fora alargado, com acessos a jusante e a montante, como se vê ainda nalgumas das gravuras antigas dedicadas a Coimbra, explicando António da Rocha Brito (séc. XX) a sua função de permissão à passagem alternada dos carros de transporte de cargas (BRITO, 1947,p. 5). 
A extremidade norte era rematada por um torreão-peagem, quadrangular, destinado à aplicação das taxas e impostos sobre quem entrava na cidade. No frontispício principal, sobre o arco de entrada, fora colocada uma lápide brasonada ladeada das esferas armilares, retirada para o Museu do Instituto de Coimbra e hoje depositada no Museu Nacional de Machado de Castro, a assinalar a empresa do Rei Venturoso concluída no ano de 1513:

O SSERENISSIMO PRINCIPE : ALTO HE MVI PODEROSO REY DOM
EMANVELL NOSO SÕR O PRIM[EI] ${ }^{\text {RO }}$ EM ESTE NOME HE QVATORZE
NA DI[G]NIDADE REALL : MÂDOV FAZER DE NOVO ESTA PÕTE
ATE AS ESFERAS HE REDIFICAR ATE A CRVZ DE SÃ F[RANCIS] ${ }^{\mathrm{CO}}$ HE
DA DITA CRVZ ATE SÃTA CRARA DE NOVO HE ACRECENTAR
ESTE TORE HE MVRO ERA DE mjll HE Vº Ejjj ANOS".

Nestas eras vivas de Fé não poderiam deixar de ficar associados, como é óbvio, as demonstrações religiosas, pelo que sobre o referido padrão estaria a representação escultórica com a Virgem Maria, segurando Cristo Menino, que se encontra igualmente no principal museu da cidade, provavelmente ambos da autoria de Diogo Pires o Moço. Próximo da entrada de Santa Clara encontrar-se-iam umas alminhas com um crucifixo (Brito, 1947,p. 5).

Mas águas do Mondego não deixariam de correr furiosamente até ao mar, pelo que a ponte acabaria por necessitar de contínuas reparações. Logo, em 1539, D. João III encarregava Diogo de Castilho de proceder às obras necessárias; em 1563, o Cardeal D. Henrique (1512|1578-1580), enquanto regente, deliberou novos reparos na mesma; e, em 1568, D. Sebastião disponibiliza as verbas para uma nova empresa reconstrutiva (BRITO, 1947, p. 10, 12/ LOUREIRO, 1874,p. 86).

Desconhecemos, no entanto, se a dimensão das obras efetuadas pelo ReiDesejado suprimiram todas as falhas identificadas, visto que, em 1583, Terzi, o suposto engenheiro militar envolvido na reconstrução do aqueduto de São Sebastião, era enviado a Coimbra para proceder à examinação para uma futura reparação na ponte real. Dois anos depois, D. Filipe I de Portugal (1527|1580-1598) determinava, por carta régia, o lançamento da finta para se proceder à reconstrução da dita ponte e das margens envolventes onde aquela assentava. Muito provavelmente, as obras não teriam sido logo executadas, pois na correspondência epistolar trocada com o arcebispo de Braga, em 1586, o monarca salientara os estragos provocados pelos "grandes invernos do anno passado" (SOUSA, 1997: 309-310).

Milton Pedro Dias Pacheco. Do aQueduto, Das fontes e Das PONTES: 
A ponte quinhentista, reformada pela última vez naquela centúria pelo arquiteto régio Fillipo Terzi, teria outras obras de consolidação até ser substituída por uma nova em Maio de $1875^{14}$, não devido ao assoreamento do leito do rio, mas sim às necessidades de permitir, com maior segurança, a passagem do trânsito rodoviário.

Setenta e nove anos depois, a estrutura de ferro assente em pilares de alvenaria deu lugar à atual ponte, uma estrutura de betão armado, dotada de tabuleiro plano e assente em cinco pilares pendulares, com talha-mares elípticos, de forma a facilitar o curso das águas fluviais. Erguida em local próximo da anterior, a nova ponte, desenhada pelo arquiteto Peres Fernandes (séc. XX) e conduzida pela Junta Autónoma de Estradas, afecta ao Ministério das Obras Públicas, seria inaugurada em 30 de Outubro de 1954.

Curiosamente, em 1950, durante as sondagens geológicas realizadas no seguimento dos estudos de engenharia, seriam encontrados, a 14 metros de profundidade, nas proximidades da margem de Santa Clara, vestígios de uma escada executada em cantaria. Pertenceriam estes achados arqueológicos à ponte real manuelina como sugeriram os engenheiros responsáveis pela última obra?

\section{CONSIDERAÇÕES FINAIS}

Aproximando-nos do fim desta jornada por alguns dos espaços mais emblemáticos da antiga Coimbra Quinhentista sentimos que muito ainda ficou por dizer. Poderíamos ter mencionado também muitas outras obras arquitetónicas relacionadas com a distribuição e fornecimento de água à cidade e que seguramente sofreram algumas diversas transformações técnicas, assim como aperfeiçoamentos materiais ao longo de todo o século XVI, mas fomos, em certa medida, obrigados a tratar somente o conjunto mais emblemático.

Sabemos, por exemplo, através das vereações de 21 de Agosto e de 24 de Setembro de 1567, que a edilidade havia planeado uma intervenção de limpeza e reparação da Fonte dos Judeus, noticiada já em 1137; ou que, em 1592, o chafariz de Sansão, junto do Mosteiro de Santa Cruz - conhecido pelas suas águas boas "para amassar o pão e para lavar o rosto porque o faz mais alvo" -, recebera, sobre um pedestal quadrangular, a estátua da personagem bíblica homónima, com cerca de dois 
metros de altura, da autoria do escultor Manuel Fernandes (séc. XVI) [Garcia, 1923: 195-196/ Dias, 1991: 28 $]^{15}$.

Outras deixam-nos algumas dúvidas quanto à data da sua execução, como a Fonte da Bica, construída junto do antigo Colégio de São Miguel, no início da Rua da Sofia e onde hoje se ergue o edifício da Caixa Geral de Depósitos. Ou, noutro caso, a Fonte da Torre de Santa Cruz, erguida no local onde mais tarde se instalou a cadeia comarcã (ficando conhecida desde então como Fonte da Cadeia), cuja água, proveniente das nascentes do Jardim da Sereia, jorravam, pelo menos desde o ano de 1541, da tromba de um elefante.

De igual modo, surgem inúmeras dúvidas quanto à data de construção do mais antigo chafariz da praça de S. Bartolomeu abastecido pelo reservatório da fonte da Sé Velha e identificado no desenho levantado em 1572, mas publicado na obra Civitates Orbis Terrarum em 1598 [Carvalho, 1942: 155,159].

Merece ainda especial menção o fontanário central do claustro do Mosteiro de Santa Maria de Celas, fundado por D. Sancha (c.1180-1229), filha de D. Sancho I, para a comunidade da Ordem de Cister, cuja estrutura se assemelha às piscinas baptismais utilizadas nos primórdios do Cristianismo. Através da documentação relativa a esta casa religiosa, sabemos que o claustro recebeu novas obras de revalorização durante o abadessado de D. Maria de Távora (séc. XVI), entre 1541 e 1572. De facto, D. João III oferecera à comunidade, no ano de 1553, um conjunto de capitéis historiados proveniente do edifício dos antigos Estudos Gerais. Porventura, teria a construção do fontanário central pertencido a D. Maria de Távora ou à sua antecessora, D. Leonor de Vasconcelos, abadessa entre 1521 e 1541, a quem se atribui a empresa mecenática da Fonte de Vimarães erguida na cerca de Celas?

Ao longo do nosso texto verificámos que o património monumental edificado associado à transposição da água ou à superação dos seus cursos naturais resultou das necessidades entretanto surgidas entre os habitantes de Coimbra.

Apesar de o conhecimento sobre esse legado histórico ter chegado até nós algo desvirtuado, confrontando-o com algumas fontes documentais existentes, é fácil demonstrar que a variedade das estruturas, localizadas outrora em pontos vitais da vida urbana, apresenta uma certa diversidade tipológica, obedecendo a programas arquitetónicos modernos e exequíveis, seguindo as exigências de utilidade, segurança e salubridade. Contudo, a modernização das suas estruturas implicaria o desvirtuamento e a destruição quase constante das suas estruturas primitivas.

Milton Pedro Dias Pacheco. Do AQueduTO, DAS FONTES E DAS PONTES: 
A estrutura orgânica dos vários monumentos confluiu numa arquitetura programada e proporcional, de acordo com os princípios válidos de funcionalidade e conforme os preceitos da época. Nalgumas estruturas despontariam as marcas da prolixa escultura manuelina; noutras as rígidas formas da escultura maneirista.

Por isso, esta importante componente situacional traduz-se na materialização de uma arquitetura própria, notável pelas condições materiais que preserva, na morfologia e função atribuída, ainda que posteriormente alterados, mas a perpetuar feições primordiais e caraterísticas que os mantêm percetíveis quanto à orgânica original.

ABSTRACT: In the $16^{\text {th }}$ century Coimbra attended a major reformation in a set of patrimonial public assets belonging to the Portuguese Crown or connected with the Catholic Church, essential architectural mechanisms responsible for the supplying of water to local residents, especially composed by scholar and religious communities. This essay deals with an assemblage of different monuments related with the architecture of water in order to enhance the analysis of major reforms that marked a historical period and an artistic taste which in part still remains in the memory of the city.

KEY WORDS: Coimbra in the $16^{\text {th }}$ century/ Water architecture / Historical monuments

\footnotetext{
${ }^{1}$ Estranhamente menciona Pinho Leal, no seu capítulo dedicado a Coimbra, que "Era Coimbra muita falta d'agua, não tendo quasi nenhuma fonte; porque os crúzios a tinham usurpado quasi toda, tendo o convento e cêrca cobertos de profusão de fontes, sem que, por bem, quisessem ceder da superabundante, para a cidade. Houve d'isto muitas queixas a varios reis que todas eram abafadas pelo enorme poderio dos frades".

${ }^{2}$ Foi classificado Monumento Nacional por Decreto de 16 de Junho de 1910, DG 136 de 23 Junho 1910.

${ }^{3}$ Entretanto, cinco anos depois, em 1937, a Direção Geral dos Edifícios e Monumentos Nacionais dirigia os primeiros trabalhos de consolidação das estruturas do aqueduto.

${ }^{4}$ Os do extremo nascente haviam sido já incorporados no largo muro da Cadeia Penitenciária da cidade, confrontando a Sul com a actual Casa Museu Dr. Elysio de Moura.

${ }^{5}$ Sobre a evolução do monumento residencial episcopal conimbricense desde as suas origens vide Milton Pedro Dias PACHECO, Por detrás de um Museu. O Paço Episcopal de Coimbra: história e memória, dissertação de Mestrado em História da Arte, especialidade em História da Arte, defendida na Faculdade de Letras da Universidade de Coimbra em 2010 (tese policopiada).

${ }^{6}$ Os bispos de Coimbra eram alcaides de Avô e não de Arouca.

7 Correspondência expedida, Vergílio CORREIA, "Ofício 8/30 enviado Chefe da Repartição do Património da Direção Geral da Fazenda Pública", 2 de Junho de 1944, fol.1.

${ }^{8}$ Vereaçôes, L. $81^{\circ}$, "Orçamento geral da receita e despesa do Concelho de Coimbra - anno economico de 1850 a 1851 ", fol.17.

${ }^{9}$ Até à instalação da canalização os residentes do Paço dispunham de uma cisterna no flanco norte.
} 
${ }^{10}$ Correspondência expedida, "Ofício no . 15/21 enviado ao Director Geral dos Edifícios e Monumentos Nacionais", 9 de Maio de 1951, fol.1.

${ }^{11}$ Para uma leitura mais pormenorizada do conjunto escultórico das gárgulas vide Catarina Alexandra Martins Fernandes Barreira, Gárgulas: representações do feio e do grotesco no contexto português. Séculos XIII a XVI, Lisboa, volume II da dissertação de Doutoramento pela Faculdade de Belas Artes da Universidade de Lisboa, 2010, pp. 560-600.

${ }^{12}$ Sobre as obras efectuadas no monumento pelos organismos estatais vide Boletim da Direcção-Geral dos Edifícios e Monumentos Nacionais - O Jardim da Manga. nº. 89, Setembro de 1957, p. 33-40, com respetivos desenhos arquitetónicos e levantamentos fotográficos anexos.

${ }^{13}$ Pinho Leal assevera que muitos dos visitantes que conheciam a cerca crúzia - correspondente em grande parte à atual Avenida Sá da Bandeira e Praça da República - afirmariam, com certo espanto, que aquela mais parecia ser uma quinta de recreio de um rei do que a de uma comunidade religiosa.

${ }^{14} \mathrm{O}$ projecto da ponte ficou a cargo do engenheiro Matias Heitor de Macedo.

${ }^{15}$ Este último chafariz teria recebido nova canalização por volta do ano de 1549 .

\section{BIBLIOGRAFIA}

\section{Fontes manuscritas e dactilografadas:}

Arquivo Central do Paço Episcopal de Coimbra (ACPEC): Livro dos Registos das Cartas de ElRey N.S. ${ }^{\text {or }}$ e da sua Secretaria, bem como para as Bullas e Breves da S. ${ }^{\text {ta }}$ Sede que se dirigiram a esta Mitra para o Governador desde Bispado de Coimbra.

Arquivo Histórico Municipal de Coimbra (AHMC), Vereações.

Arquivo da Universidade de Coimbra (AUC), Cabido de Coimbra.

Biblioteca da Academia de Ciências de Lisboa (BACL), João d'Almeida SOARES, Vida e morte de Dom Affonço Castelbranco Bispo de Coimbra, Senhor de Coja e Alcayde mór de Arouca [sic], Vizo Rey deste Reyno dito Portugal, Série Vermelha de Manuscritos, manuscrito194.

Direcção Geral dos Edifícios e Monumentos Nacionais (Coimbra e Lisboa) / Instituto de Habitação e Reabilitação Urbana (IHRU/DGEMN), Paço Episcopal de Coimbral Museu Machado de Castro.

Museu Nacional de Machado de Castro (MNMC), Copiadores e Correspondência expedida. 


\section{Obras de consulta:}

ABREU, Antonio de. Conquista, Antiguidade, e Nobreza da mui insigne, e inculta cidade de Coimbra. Lisboa: Impressão Regia, 1807.

ALONSO OSA, Carlos. La Fundación del Colegio Agustiniano de N.tra S.ra de Gracia de Coimbra (1543-1551). Coimbra: s.e, 1991.

ALMEIDA, Fortunato de. D. Jorge de Almeida e D. Afonso de Castelo Branco. Instituto de Coimbra. Coimbra, v. LXXI, p. 57-64, 1924.

AZEVEDO, Carlos Moreira (Direcção de). História Religiosa de Portugal. Rio de Mouro: Círculo de Leitores, 2000.

Boletim da Direcção-Geral dos Edifícios e Monumentos Nacionais - O Jardim da Manga. №. 89, Setembro de 1957.

BORGES, Nelson Correia. Arquitectura Monástica Portuguesa na Época Moderna (Notas de uma investigação). Mvseu. Porto, IV série, no 7, p. 31-59, 1998.

BORGES, Nelson Correia. Coimbra e sua região. Lisboa: Presença, 1987.

BOTELHO, Bernardo de Brito. Historia Breve de Coimbra. Lisboa: Imprensa Nacional, 1873.

BRANDÃO, Mário. Cartas de Frei Brás de Braga para os priores do Mosteiro de Santa Cruz de Coimbra. Coimbra: Imprensa Académica, 1937.

BRITO, A. da Rocha. Filipe Tércio e a Ponte Real de Coimbra. Arquivo Coimbrão, v. X, Coimbra, p. 1-48, 1947.

CARVALHO, Branquinho de. Livro II da Correia. Arquivo Coimbrão. Coimbra, v. XV, p. 134-229, 1957.

CARVALHO, Francisco Augusto Martins de. Fontes e chafarizes de Coimbra e suas imediações. Arquivo Coimbrão, Coimbra, v. VI, p. 154-203, 1942.

CARVAlHO, João. Diário da Peste de Coimbra. Lisboa: Fundação Calouste Gulbenkian, 1994.

CARVALHO, Pedro. O Forum de Aeminium. Lisboa: Instituto Português de Museus, 1998. 
CASTRO, Augusto de. Guia Historico do viajante em Coimbra e arredores. Coimbra: Imprensa da Universidade, 1867.

CORREIA, Virgílio. Uma descrição quinhentista do Mosteiro de Santa Cruz. $O$ Instituto. v. 79, $\mathrm{n}^{\circ}$ 1, p. 28-54,1930.

CORREIA, Vergílio, e, GONÇALVES, António Nogueira. Inventário Artístico de Portugal - Cidade de Coimbra. Lisboa: Academia Nacional de Belas Artes, 1947.

CRAVEIRO, Maria de Lurdes. O Renascimento em Coimbra: modelos e programas arquitectónicos. Coimbra: 2 volumes, Dissertação de Doutoramento defendida na Faculdade de Letras da Universidade de Coimbra na especialidade de História da Arte, 2002 [tese policopiada].

DIAS, Pedro. A Arquitectura de Coimbra na transição do gótico para a Renascença (1490-1540). Coimbra: Epartur, 1982.

DIAS, Pedro. A oficina de Tomé Velho, construtor e escultor do Maneirismo Coimbrão. Actas do VI Simpósio Luso-Espanhol da História da Arte. Viseu: p. 15-62, 1991.

FIGUEIREDO, Borges de. Coimbra antiga e moderna. Coimbra: Almedina, 1996.

GARCIA, Prudêncio Quintino. Artistas de Coimbra. Documentos para as suas biografias. Coimbra: Imprensa da Universidade, 1923.

GOMES, Saul António. Os Cónegos Regrantes de Santo Agostinho em tempos de reforma: 1500-1530, Actas do III Congresso Histórico de Guimarães. Guimarães: Câmara Municipal, p. 255-281, 2004.

GONÇALVES, António Nogueira. Estudos da História da Arte da Renascença. Porto: Paisagem Editora, 1984.

GOUVEIA, Ayres de. Indice Chronologico dos pergaminhos e foraes existentes no Archivo da Camara Municipal de Coimbra. Coimbra: Imprensa Literária/ Imprensa da Universidade, 1875.

LEAL, Augusto Pinho. Portugal Antigo e Moderno. Lisboa: Lisboa Editora de Mattos Moreira \& Companhia, 1874.

LOUREIRO, José Pinto. A administração coimbrã no século XVI. Elementos para a sua história. Arquivo Coimbrão. Coimbra, n. ${ }^{\circ}$ V, p. 1-207, 1940. 
LOUREIRO, Adolfo Ferreira. Memória sobre o Mondego e barra da Figueira. Lisboa, Imprensa Nacional, 1874.

MARKL, Dagoberto, e, PEREIRA, Fernando António. História da Arte em Portugal. O Renascimento. Lisboa: Edições Alfa, 1986.

MILLER, Maureen C.. The Bishop Palace. Architecture and Authority in Medieval Italy, Ithaca/New York: Cornell University Press, 2000.

NOGUEIRA, Pedro Álvares. Livro das vidas dos Bispos da Sé de Coimbra (edição com coordenação de Manuel Augusto RODRIGUES e transcrição de Maria Teresa Nobre VELOSO). Coimbra: Arquivo da Universidade de Coimbra, 2003.

PACHECO, Milton Pedro Dias (a). Entre a cidade e o campo. As casas dos bispos de Coimbra. Actas do ciclo de conferências A Casa. Coimbra, [34 p./ no prelo].

PACHECO, Milton Pedro Dias. Por detrás de um Museu. O Paço Episcopal de Coimbra: história e memória. Coimbra: dissertação de Mestrado em História da Arte, especialidade em História da Arte, apresentada à Faculdade de Letras da Universidade de Coimbra, Faculdade de Letras da Universidade de Coimbra, 2009. [tese policopiada] PACHECO, Milton Pedro Dias (b). Para governar e desfrutar. As residências palatinas dionisínas. Actas do Congresso Internacional Dom Dinis. 750 anos do seu nascimento. Lisboa, [38 p./ no prelo].

PAIVA, José Pedro. Os Bispos de Portugal e do Império (1495-1777). Coimbra: Imprensa da Universidade de Coimbra, 2006.

PAIVA, José Pedro. A diocese de Coimbra antes e depois do Concílio de Trento: D. Jorge de Almeida e D. Afonso de Castelo Branco. Sé Velha de Coimbra: culto e cultura. Coimbra, p. 225-253, 2005.

PIMENTEL, António Filipe. As Empresas Artísticas do Bispo-Conde D. Afonso Castelo Branco. Mundo da Arte, Coimbra, ns. 8-9, p. 54-68, 1982.

PIMENTEL, António Filipe. A Morada da Sabedoria. Coimbra: Almedina, 2005.

PIMENTEL, António Filipe. Poder, corte e palácio real: os palácios manuelinos e a reforma quinhentista da alcáçova de Coimbra. Universidade(s), Histórias, Memórias, Perspectivas. Coimbra, v. II, p. 231-253. 1991. 
PIMENTEL, António Filipe. A Sagração do Reino em torno do(s) projecto(s) da Sé Velha. separata da Artis, Revista do Instituto de História da Arte da Faculdade de Letras de Lisboa. Lisboa, $\mathrm{n}^{\circ}$. 3, 2004.

RÉVAH, Israel Salvator. La "Descripçam e debuxo do moesteyro de Santa Cruz de Coimbra" imprimée en 1541. Boletim da Biblioteca da Universidade de Coimbra. Coimbra, v. XXIII, 1957.

RODRIGUES, Manuel. Biblioteca e Bens de D. Francisco de Lemos e da Mitra de Coimbra. Coimbra: Publicação do Arquivo da Universidade de Coimbra, 1984.

SILVA, Armando da. Anais do Município de Coimbra (1840-1869). Coimbra: Edição da Biblioteca Municipal de Coimbra, 1972-73.

SOUSA, Aurélio de. Braga e o Arcebispado no tempo de D. Fr. Bartolomeu dos Mártires (1559-1582). Revista da Faculdade de Letras. História, v. XIV, Porto, p. 271330, 1997,

TRINDADE, Luísa. A Casa Corrente em Coimbra. Dos finais da Idade Média aos inícios da Época Moderna. Coimbra: Câmara Municipal de Coimbra, 2002.

VASCONCELOS, António de. António de Vasconcelos perpetuado nas páginas do "Correio de Coimbra" (1922-1941), (coordenação de Manuel Augusto RODRIGUES). Coimbra: Arquivo da Universidade de Coimbra, 2000.

VASCONCELOS, António de. A Sé Velha de Coimbra, Coimbra: Arquivo da Universidade de Coimbra, 1993. 